\title{
Analisis kemampuan mendribbling bola menggunakan massed and distributed practice pada sepakbola
}

\author{
Muhammad Muhajirin a *, Sugeng Purwanto ${ }^{b}$ \\ Universitas Negeri Yogyakarta. Jalan Colombo No. 1, Yogyakarta, 55281, Indonesia. \\ a muhammadmuhajirin65@gmail.com; b sugeng_purwanto@uny.ac.id \\ * Coressponding Author.
}

Received: 15 January 2021; Revised: 20 January 2021; Accepted: 22 January 2021

Abstrak: Penelitian ini bertujuan untuk mengungkapkan: (1) perbedaan pengaruh metode massed dan distributed practice (2) perbedaan pengaruh bagi pemain yang memiliki koordinasi mata kaki tinggi dan koordinasi mata-kaki rendah (3) interaksi yang signifikan antara metode massed dan distributed practice serta koordinasi mata kaki terhadap kemampuan menggiring bola dalam permainan sepakbola pada pemain Green Boys FC Selengen usia 12-17 tahun. Populasi penelitian ini adalah 37 pemain Green Boys FC Selengen usia 12-17 tahun. Instrumen untuk mengukur koordinasi mata-kaki menggunakan Mithcel Soccer Test dan untuk mengukur kemampuan menggiring bola menggunakan tes menggiring bola dari Nurhasan (2011). Teknik analisis data yang digunakan adalah ANOVA dua jalur. Hasil penelitian adalah sebagai berikut: (1) Ada perbedaan pengaruh yang signifikan antara metode massed dan distributed practice terhadap kemampuan menggiring bola dalam permainan sepakbola pada pemain Green Boys FC Selengen usia 12-17 tahun. Metode distributed practice lebih baik dibandingkan dengan metode massed practice. (2) Ada perbedaan pengaruh yang signifikan kemampuan koordinasi mata kaki tinggi dan koordinasi mata kaki rendah terhadap kemampuan menggiring bola dalam permainan sepakbola. Pemain dengan kemampuan koordinasi mata-kaki tinggi lebih baik dibandingkan dengan pemain dengan kemampuan koordinasi mata-kaki rendah. (3) Ada interaksi yang signifikan antara metode massed dan distributed practice dan koordinasi mata-kaki tinggi dan koordinasi mata-kaki rendah terhadap kemampuan menggiring bola dalam permainan sepakbola pada pemain Green Boys FC Selengen usia 12-17 tahun.

Kata Kunci: massed practice, distributed practice, koordinasi mata kaki, menggiring bola

\section{Analysis of the ability to dribble the ball using soccer drills in bulk and distributed}

Abstract: This research aims to reveal: (1) effect differences between massed and distributed practice method on the ability in dribbling, (2) effect difference among players with high eye-foot coordination and low eye-foot coordination on the ability in dribbling, and (3) the significant interaction between the massed and distributed practice method as well as the eye-foot coordination on the ability in dribbling of the footballers of Green Boys FC Selengen ages 12-17 years. The population was 37 footballers of Green Boys FC Selengen ages 12-17 years. The instruments to measure eye-foot coordination was Mithcel Soccer Test and the test to measure dribbling ability was a test of Nurhasan (2011). The data analysis technique used was the two-way ANOVA. The results are as follows. (1) There is a significantly different effect of massed and distributed practice method on the ability in dribbling in the game of football of footballers of Green Boys FC Selengen ages 12-17 years. The distributed practice method is better than massed practice method. (2) There is a significantly different effect of the ability of the eye-foot coordination and low eye-foot coordination on the ability in dribbling in the game of football. The players with the high ability in high eye-foot coordination compared to those with the ability of the low eye-foot coordination. (3) There is a significant interaction between massed and distributed practice method with high eye-foot coordination and low eye-foot coordination on the ability in dribbling in the game of football of the footballers of Green Boys FC Selengen ages 12-17 years.

Keywords: massed practice, distributed practice,eye-foot coordination, dribble

How to Cite: Muhajirin, M., \& Purwanto, S. (2021). Analisis kemampuan mendribbling bola menggunakan massed and distributed practice pada sepakbola. Sepakbola, 1(1), 16-22. doi:http://dx.doi.org/10.33292/sepakbola.v1i1.92 
Sepakbola, 1 (1), 2021, 17

Yanuar Dian Pradana, Hari Amirullah Rachman

\section{PENDAHULUAN}

Olahraga merupakan aktivitas yang bermanfaat bagi setiap insan manusia di dunia, melalui olahraga tentunya mampu menjaga kesehatan jasmani dalam hidup kita. Dalam olahraga permainan seperti olahraga permainan sepakbola yang merupakan olahraga yang paling terkenal di dunia, mampu untuk mengembangkan berbagai macam aspek dalam diri seseorang seperti aspek fisik, teknik, emosi dan mental seseorang.

Sepakbola merupakan olahraga yang dimainkan oleh dua tim, dimana masing-masing tim terdiri dari 11 orang pemain dan dimainkan dalam waktu 2 x 45 menit. Sepakbola merupakan salah suatu cabang olahraga yang paling digemari di seluruh dunia yang bisa dimainkan oleh semua orang baik laki-laki maupun perempuan secara berkelompok. Sepakbola merupakan olahraga yang merakyat, ekonomis dan mudah dimainkan oleh semua golongan masyarakat, baik masyarakat golongan atas ataupun masyarakat golongan bawah. Sepakbola merupakan permainan yang esensial untuk melatih masa depan anak muda dan mendorong pembauran anak muda dalam masyarakat.

Sepakbola dapat menjadi wadah yang baik untuk memahami nilai-nilai seperti saling menghargai, solidaritas, saling mendukung, saling berbagi dan sebagainya. Namun karena sepakbola adalah aktivitas yang membutuhkan teknik dan koordinasi gerak yang baik untuk melakukannya, maka pemain sepakbola harus memiliki aspek tersebut agar mempunyai kemampuan yang baik dalam bermain sepakbola dan harus berlatih dengan baik dan benar untuk mencapainya.

Pada pemain sepakbola, kebutuhan akan kemampuan teknik yang baik tentunya akan menunjang kemampuan seorang pemain dalam permainan sepakbola, karena dalam permainan sepakbola dibutuhkan kualitas teknik yang baik dalam mendukung penampilan seorang pemain sepakbola. Untuk mendukung mencapai penampilan terbaik (top performance) pemain sepak bola harus menguasai teknik dasar bermain sepakbola dengan baik dan benar, sehingga dapat mengasilkan prestasi yang baik juga. Adapun kebutuhan teknik dasar yang harus dimiliki pemain sepakbola yaitu seperti passing, dribbling, heading dan shooting, akan tetapi dribbling merupakan teknik yang utama harus dikuasai. Menggiring bola (dribbling) diperlukan bagi pemain sepakbola sebab tanpa melakukan driblling atau menggiring bola tentunya permainan sepakbola tidak akan bisa berjalan dengan lancar.

Kemampuan dribbling penting yang harus ada dan dimiliki oleh setiap pemain sepakbola dalam mendukung pencapain keterampilan motorik dalam bermain sepakbola. Kemampuan dribbling diperlukan dalam keterampilan bermain sepakbola karena dengan memiliki kemampuan menggiring (dribbling) yang baik akan mendukung kemampuan seorang pemain dalam bermain sepakbola.

Mielke (2007) menyatakan bahwa dribble adalah keterampilan dasar dalam sepakbola karena semua pemain harus mampu menguasai bola saat sedang bergerak, berdiri, atau bersiap melakukan operan atau tembakan. Didalam permainan sepakbola dibutuhkan kecermatan dalam bergerak saat melakukan dribbling, seperti saat berhadapan dengan lawan, melakukan penetrasi, mencari posisi yang baik agar teman leluasa memberikan umpan. Hal ini tentunya dipengaruhi oleh koordinasi yang di miliki oleh setiap pemain sepakbola.

Koordinasi menurut Hariono (2006); Schmidt dan Wrisberg (2008); Siswantoyo (2014) adalah perpaduan gerak dari dua atau lebih persendian, yang satu sama lainnya berkaitan dalam menghasilkan suatu keterampilan gerak. Irianto (2004) juga mengatakan bahwa koordinasi adalah kemampuan melakukan gerak pada berbagai tingkat kesukaran dengan cepat dan tepat secara efisien dan hampir semua cabang olahraga memerlukan koordinasi. Hal ini dapat diartikan bahwa baik tidaknya koordinasi yang dimiliki pemain akan memberikan atau mempengaruhi kemampuannya menggiring bola (dribbling) dalam bermain sepakbola.

Koordinasi yang diperlukan dalam keterampilan bermain sepakbola yaitu koordinasi matakaki dan merupakan salah satu kemampuan fisik. Mata sebagai indera pengelihatan merupakan salah satu yang menerima rangsangan untuk diteruskan ke otak dan diproses dengan respon yang berbentuk gerakan seperti menggiring bola. Pengaruh koordinasi mata-kaki dalam kemampuan menggiring bola (dribbling) dalam bermain sepakbola sangatlah dominan, hal tersebut dapat telihat apabila pemain yang koordinasi mata-kaki dalam kemampuan dribbling atau menggiring 
bolanya kurang baik, maka akan sulit bagi seorang pemain untuk bermain sepakbola secara terampil dan optimal. Karena koordinasi mata-kaki dalam kemampuan dribbling atau menggiring bola yang baik dapat mempengaruhi penampilan pemain, baik dalam latihan maupun dalam pertandingan. Dengan demikian dapat dikatakan bahwa koordinasi mata kaki dalam kemampuan menggiring bola (dribbling) yang baik adalah suatu persyaratan dalam usaha pencapaian prestasi maksimal bagi pemain dalam bermain sepakbola.

Pengamatan penulis saat melakukan observasi pada Tim Green Boys. FC Selengen Usia 1217 Tahun, kondisi kualitas koordinasi mata kaki dalam kemampuan menggiring bola (dribbling) pada pemain masih kurang baik, seperti saat melakukan dribbling, pemain-pemain Green Boys. FC Selengen Usia 12-17 Tahun cepat kehilangan bola akibat melakukan dribbling yang tidak sempurna dan tidak bisa mengontrol bola tetap berada di dekat kakinya saat dribbling dilakukan, pandangan saat melakukan dribbling masih fokus dengan bola tidak mengarah ke depan, posisi bola dengan kaki saat melakukan dribbling masih jauh sehingga memudahkan lawan merebutnya, tidak mampu melakukan driblling dengan baik saat akan melewati hadangan lawan dan tidak adanya kombinasi dribbling yang dilakukan oleh para pemain Green Boys. FC Selengen Usia 1217 Tahun.

Latihan teknik menggiring bola (dribbling) yang dilakukan oleh pemain Green Boys. FC Selengen Usia 12-17 Tahun yang di instruksikan oleh pelatih terlihat belum maksimal, masih banyak pemain yang melakukan gerakan yang salah seperti saat melakukan dribbling dengan menggunakan kura-kura kaki, baik bagian dalam maupun luar saat latihan berlangsung. Dalam proses latihan yang dilakukan terlihat pemain-pemain Green Boys. FC Selengen Usia 12-17 Tahun bergerak kurang maksimal saat latihan dan terlihat jenuh, itu dikarenakan kurangnya kualitas kemampuan dalam meggiring bola (dribbling) dan koordinasi mata-kaki yang dimiliki para pemain dan juga dikarenakan latihan yang diberikan kurang bervariasi.

Menurut Miller (2012) menyatakan, "koordinasi, fleksibilitas, dan sentuhan diperlukan, di bawah tantangan penuh dari lawan mencoba untuk memenangkan bola, sulit untuk menguasai". Menggiring bola sangat penting dikuasai, sebab jika seorang pemain dapat melakukan menggiring bola secara efektif dapat memberikan keuntungan yang sangat besar dalam sebuah tim. Seorang pemain harus mengerti kapan harus melakukan menggiring bola, kapan pemain harus melewati lawan dan membongkar pertahanan lawan. Dengan memiliki kemampuan dribbling bola yang baik serta efektif, seorang pemain dapat melakukan penetrasi untuk mengacak-acak pertahanan lawan.

Kemampuan dribbling sepakbola tidak terlepas dari dukungan kemampuan kondisi fisik yang baik, salah satu faktor yang dapat mempengaruhi kemampuan dribbling sepakbola yaitu koordinasi mata-kaki. Koordinasi mata-kaki berperan terhadap gerakkan dribbling sepakbola, yaitu pada saat menggiring bola seorang pemain bola harus memperhatikan bola dan situasi permainan. Pada saat menggiring bola seorang pemain tidak harus menunduk terus memperhatikan letak dengan terus melihat bola, tetapi harus memperhatikan situasi permainan.

Saat menjalani pertandingan pemain-pemain Green Boys. FC Selengen Usia 12-17 Tahun sering kehilangan bola saat melakuan dribbling dan sulit atau tidak mampu melewati lawan dan berduel dengan lawan, itu diakibatkan karena kemampuan dribbling yang kurang baik yang dimiliki oleh pemain-pemain Green Boys. FC Selengen Usia 12-17 Tahun. Kurangnya koordinasi mata-kaki yang dimiliki pemain-pemain juga berakibat pada penampilan pemain saat melakukan dribbling atau menggiring bola yang dilakukan sehingga para pemain sering melakukan kesalahan saat melakukan dribbling, dari 11 pemain 7 pemain sering kehilangan bola saat melakukan $d r i b$ bling. Pelatih selaku pengajar kurang memahami tentang metode latihan, dan hanya mengandalkan pengalaman pribadinya saja tanpa pernah mengikuti pelatihan sebagai pelatih sepakbola sebelumnya sehingga kurang mampu dalam melaksanakan profesinya secara kompeten, mereka belum berhasil melaksanakan tanggung jawab untuk melatih pemain secara sistematis melalui Tim Green Boys. FC Selengen Usia 12-17 Tahun. Tim Green Boys. FC Selengen Usia 12-17 adalah Tim sepakbola yang berada di Desa Selengen Kecamatan Kayangan Kabupaten Lombok Utara Nusa Tenggara Barat yang memiliki struktur organisasi atau kepengurusan yang baik mulai dari ketua, wakil ketua, sekertaris, bendahara, dan anggota. Sedangkan yang menjadi penanggug jawabnya adalah Kepala Desa Selengen sendiri. Tim Green Boys. FC Selengen Usia 12-17 Tahun 
selalu aktif dan rutin mengikuti even-even resmi yang diselenggarakan oleh PSSI maupun yang di selenggarakan oleh swasta di Kabupaten Lombok Utara Nusa Tenggara Barat.

Peran pelatih dalam upaya peningkatan kemampuan pemain dalam menguasai keterampilan bermain sepakbola sangat tergantung kreativitas seorang pelatih itu sendiri, dalam memberdayakan segala potensi yang ada. Kreativitas seorang pelatih sepakbola tercermin dalam memilih dan menentukan metode latihan dalam permainan sepakbola sesuai dengan kemampuan dan sarana yang ada pada Tim Green Boys. FC Selengen Usia 12-17 Tahun, sehingga dapat memberikan motivasi agar pemain dapat berpartisipasi secara aktif sesuai dengan potensinya.

Penerapan metode latihan yang tepat dalam proses latihan, seperti metode latihan massed dan distributed diharapkan oeleh penulis akan memberikan dampak yang baik bagi perkembangan kualitas pemain khusunya dalam kemampuan dribbling dan koordinasi mata kaki bagi pemain sepakbola yang ada pada Tim Green Boys. FC Selengen Usia 12-17 Tahun, dengan menerapkan dua metode latihan yang berbeda maka pelatih akan mengetahui mana metode latihan yang tepat yang dapat digunakan dalam melatih kemampuan dribbling bagi pemain sepakbola yang ada pada Tim Green Boys. FC Selengen Usia 12-17 Tahun.

Menerapkan metode latihan massed dan distributed practice dalam proses latihan kemampuan dribbling juga diharapkan akan memberikan peluang bagi pelatih dalam memanfaatkan fasilitas yang tersedia secara maksimal sehingga tidak ada alasan bagi pelatih terhambat dalam menjalankan proses latihan permainan sepakbola dengan baik. Penulis juga mengharkan bahwa dalam penerapan metode latihan massed dan distributed practice dalam proses latihan kemampuan dribbling juga akan memberikan kemudahan bagi pelatih memanfaatkan fasilitas yang ada dalam melatih pada Tim Green Boys. FC Selengen Usia 12-17 Tahun Kecamatan Kayangan Kabupaten Lombok Utara Nusa Tenggara Barat.

Dalam proses latihan juga harus memerlukan kerjasama yang baik antara pelatih dan pemain untuk mendukung kelancaran proses latihan. Karakteristik pelatih dan atlet yang baik adalah yang memiliki motivasi yang baik dalam berlatih. Motivasi yang baik akan memungkinkan setiap individu dapat bekerja lebih baik dalam kelompoknya. Penampilan yang baik pasti ditunjukkan dengan adanya motivasi dan keterampilan yang baik pula, sehingga memungkinkan tujuan yang mereka tetapkan dapat dicapai dengan baik.

Penting bagi setiap pemain khususnya pemain sepakbola mempunyai koordinasi mata kaki yang baik guna untuk menunjang kemampuannya menggiring bola (dribbling) dalam bermain sepakbola. Karena dalam menggiring bola (dribbling) membutuhkan gerakan yang cukup komplek dan bermain sepak bola merupakan gabungan dari berbagai unsur seperti gerakan berlari, mengontrol, menyentuh bola serta melihat situasi di sekeliling lapangan.

\section{METODE}

Desain yang digunakan dalam penelitian ini adalah metode eksperimen dengan menggunakan rancangan faktorial $2 \times 2$. Metode ini bersifat menguji (validation) yaitu menguji pengaruh satu atau lebih variabel terhadap variabel lain. (Sukmadinata, 2015) menyatakan penelitian eksperimen merupakan pendekatan penelitian kuantitatif yang paling penuh, dalam arti memenuhi semua persyaratan untuk menguji hubungan sebab akibat.

Sudjana (2002) menyatakan eksperimen faktorial adalah desain yang dapat memberikan perlakuan/manipulasi dua variabel bebas atau lebih pada waktu yang bersamaan untuk melihat efek masing-masing variabel bebas, secara terpisah dan bersamaan terhadap variabel terikat dan efek-efek yang terjadi akibat adanya interaksi beberapa variabel.

Tabel 1. Rancangan Penelitian Faktorial 2 x 2

\begin{tabular}{ccc}
\hline Metode Latihan (A) & Massed Practice (A1) & Distributed Practice (A2) \\
Koordinasi Mata Kaki (B) & A1. B1 & A2. B1 \\
Tinggi (B1) & A1. B2 & A2. B2 \\
Rendah (B2) & Manda
\end{tabular}

Keterangan: 
A1B1: Kelompok atlet yang dilatih menggunakan metode latihan massed practice dengan koordinasi mata kaki tinggi

A2B1: Kelompok atlet yang dilatih menggunakan metode latihan distributed practice dengan koordinasi mata kaki tinggi

A1B2: Kelompok atlet yang dilatih menggunakan metode latihan massed practice dengan koordinasi mata kaki rendah

A2B2: Kelompok atlet yang dilatih menggunakan metode latihan distributed practice dengan koordinasi mata kaki rendah

Populasi dalam penelitian ini adalah pemain Green Boys FC Selengen Usia 12-17 Tahun berjumlah 37 atlet. Ciri-ciri populasi adalah pemain Green Boys.FC Selengen, berusia 12-17 tahun, kehadiran miminal $75 \%$, dan telah berlatih minimal 3 bulan. Jumlah populasi 37 atlet yang diambil menggunakan teknik random sampling berdasarkan cara membagi kelompok yang di tes koordinasinya..

Variabel dalam penelitian ini terdiri atas dua variabel bebas (independent) manipulative, yaitu metode latihan massed practice dan distributed practice, sedangkan sebagai variabel bebas atributif, yaitu koordinasi mata kaki. Kemudian variabel terikat (dependent) adalah menggiring bola.

\section{Instrumen Penelitian}

\section{Tes Koordinasi Mata kaki}

Untuk mengukur kualitas koordinasi mata kaki menggunakan Mithcel Soccer Test dengan Validitas tes $=0,84$ (Jika dianalisis memakai rumus Rank Order Corelation dari Spearman) dan 0,76 (Jika dianalisis memakai rumus Product Moment dari Pearson). Sedangkan Reabilitasnya = 0,93 (Jika dianalisis memakai rumus Rank Order Corelation dari Spearman) dan 0,89 (Jika dianalisis memakai rumus Product Moment dari Pearson).

Tes Menggiring Bola (Dribbling)

Mengukur kemampuan menggiring bola (dribbling) menggunakan tes Tes Menggiring Bola (dribbling) dari Nurhasan (2001, pp.157-161), dengan Validitas tes $=0,548$ dan Reabilitas $=0,706$. Melalui teknik statistik deskriptif dengan frekuensi dan persentase melalui pengkategorian.

\section{Teknik Analisis Data}

Teknik analisis data yang digunakan dalam penelitian ini dengan menggunakan SPSS 20 yaitu dengan menggunakan ANOVA dua jalur (ANOVA two-way) pada taraf signifikansi $\alpha=0,05$.

Selanjutnya untuk membandingkan pasangan rata-rata perlakuan digunakan uji Tukey (Sudjana, 2002). Mengingat analisis data penelitian dilakukan dengan mengunakan ANOVA, maka sebelum sampai pada pemanfaatan ANOVA dua jalur (ANOVA two-way) perlu dilakukan uji prasyarat yaitu meliputi: (1) uji normalitas dan (2) uji homogenitas varian dan uji hipotesis.

\section{HASIL DAN PEMBAHASAN}

\section{Deskripsi Data Penelitian}

Data hasil penelitian ini adalah berupa data pretest dan posttest yang merupakan gambaran umum tentang masing-masing variabel yang terkait dalam penelitian. Pengambilan data pretest dimulai pada hari Minggu, 15 Februari 2016 pukul 16.00-18.00 WIB sedangkan untuk pengambilan data posttest dilaksanakan pada hari Kamis, 21 April 2016 pukul 16.00-18.00 WIB.

Pemberian perlakuan (treatment) dilaksanakan sebanyak 24 kali pertemuan, dengan frekuensi 3 (tiga) kali pertemuan dalam satu Minggu, yaitu setiap hari Minggu, Rabu, dan Jum'at. Data pretest dan posttest hasil tes kemampuan menggiring bola (dribbling) dalam permainan sepak bola pada pemain Green Boys. FC Selengen Usia 12-17 Tahun disajikan pada Tabel 2.

Berdasarkan analisis statistik uji normalitas yang telah dilakukan dengan menggunakan uji $Z$ Kolmogorov Smirnov, pada semua data pretest dan posttest menggiring bola didapat dari hasil uji normalitas data nilai signifikansi $p>0,05$, yang berarti data berdistribusi normal. 
Sepakbola, 1 (1), 2021, 21

Yanuar Dian Pradana, Hari Amirullah Rachman

\begin{tabular}{ccccccr}
\hline & \multicolumn{7}{c}{ Koordinasi Mata Kaki Tinggi } \\
\cline { 2 - 7 } No. & \multicolumn{7}{c}{ Latihan Massed Practice (A1B1) } & \multicolumn{4}{c}{ Latihan Distributed Practice (A2B1) } \\
\cline { 2 - 7 } 1. & Pretest & Posttest & Selisih & Pretest & Posttest & Selisih \\
2. & 32,2 & 30,21 & 1,81 & 33,24 & 26,29 & 6,95 \\
3. & 30,3 & 28,02 & 2,11 & 30,28 & 26,04 & 4,24 \\
4. & 33,1 & 30,09 & 3,12 & 31,24 & 27,38 & 3,86 \\
5. & 34,2 & 31,27 & 3,15 & 35,31 & 27,47 & 7,84 \\
\hline & 31,7 & 28,14 & 3,13 & 32,52 & 26,19 & 6,33 \\
\cline { 2 - 7 } No. & \multicolumn{7}{c}{ Loordinasi Mata Kaki Rendah } \\
\cline { 2 - 7 } & \multicolumn{7}{c}{ Latihan Massed Practice (A1B2) } & Latihan Distributed Practice (A2B2) \\
\hline 1. & 33,24 & Posttest & Selisih & Pretest & Posttest & Selisih \\
2. & 30,28 & 26,29 & 6,95 & 36,25 & 34,47 & 1,78 \\
3. & 31,24 & 27,38 & 4,24 & 36,22 & 34,58 & 2,38 \\
4. & 35,31 & 27,47 & 3,86 & 37,57 & 35,19 & 1,2 \\
5. & 32,52 & 26,19 & 7,84 & 36,49 & 35,29 & 2,36 \\
\hline
\end{tabular}

Tabel 3. Deskriptif Statistik Pretest dan Posttest Menggiring Bola

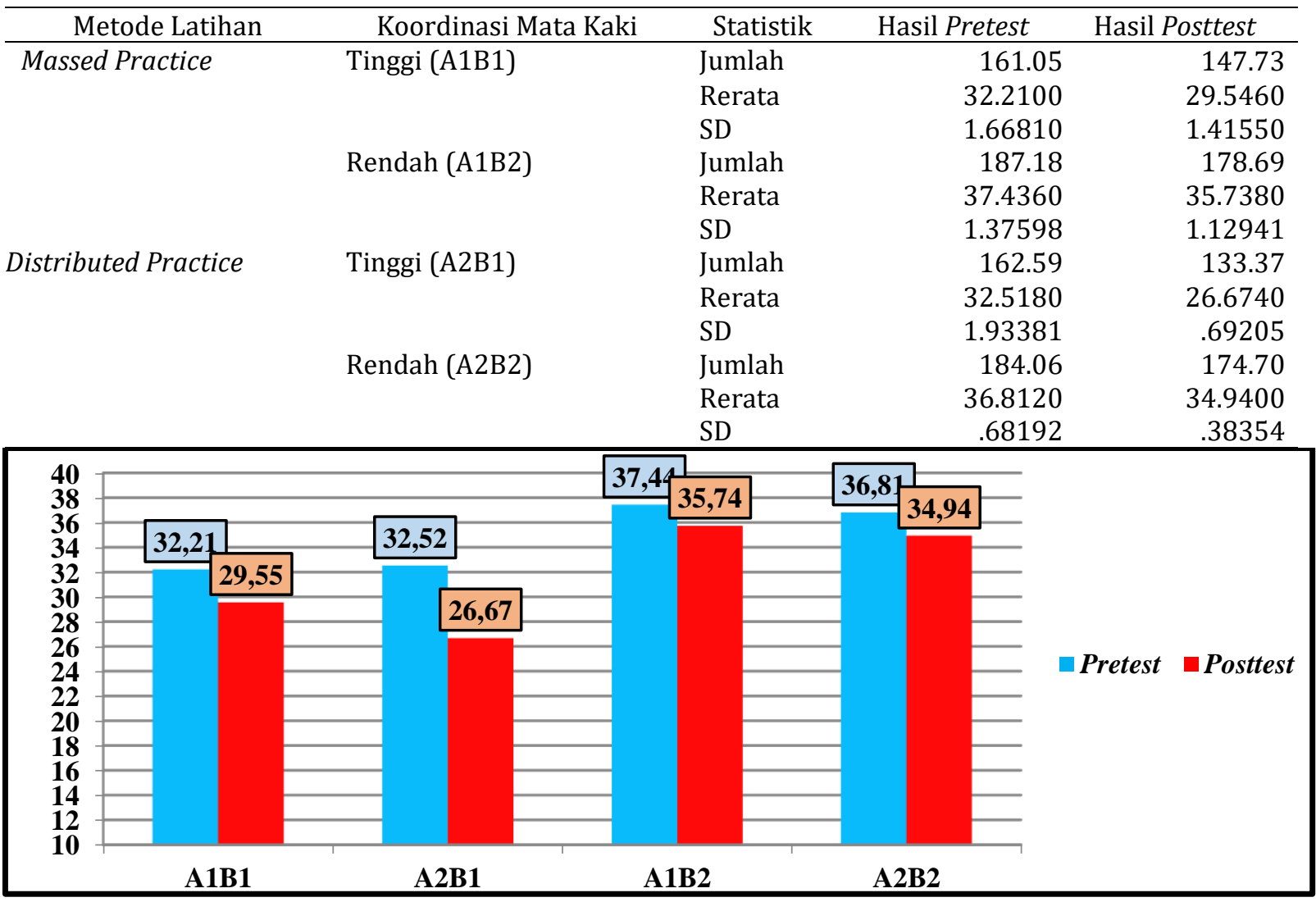

Gambar 1. Diagram Batang Pretest dan Posttest Menggiring Bola

Keterangan:

A1B1: Kelompok atlet yang dilatih menggunakan metode latihan massed practice dengan koordinasi mata kaki tinggi

A2B1: Kelompok atlet yang dilatih menggunakan metode latihan distributed practice dengan koordinasi mata kaki tinggi

A1B2: Kelompok atlet yang dilatih menggunakan metode latihan massed practice dengan koordinasi mata kaki rendah

A2B2: Kelompok atlet yang dilatih menggunakan metode latihan distributed practice dengan koordinasi mata kaki rendah 
Sepakbola, 1 (1), 2021, 22

Yanuar Dian Pradana, Hari Amirullah Rachman

\begin{tabular}{lccc}
\hline \multicolumn{1}{c}{ Data } & $P$ & Signifikansi & Keterangan \\
\hline Pretest A1B1 & 1,000 & 0,05 & Normal \\
Posttest A1B1 & 0,914 & & Normal \\
Pretest A2B1 & 1,000 & & Normal \\
Posttest A2B1 & 0,721 & Normal \\
Pretest A1B2 & 0,959 & & Normal \\
Posttest A1B2 & 0,877 & Normal \\
Pretest A2B2 & 0,823 & & Normal \\
Posttest A2B2 & 0,664 & & Normal \\
\hline
\end{tabular}

Tabel 5. Uji Homogenitas

\begin{tabular}{cccccc}
\hline Kelompok & Levene Statistic & df1 & df2 & Sig. & Ket. \\
\hline Pretest & 2.192 & 1 & 18 & 0.16 & Homogen \\
Posttest & 4.841 & 1 & 18 & 0.11 & Homogen \\
\hline
\end{tabular}

Berdasarkan analisis statistik uji homogenitas yang telah dilakukan dengan menggunakan uji Levene Test. Pada pretest diperoleh nilai signifikansi sebesar 0,484 $\geq 0,05$. Hal ini berarti dalam kelompok data memiliki varian yang homogen. Demikian juga dengan hasil perhitungan pada posttest didapat nilai signifikansi sebesar $0,407 \geq 0,05$. Hal berarti dalam kelompok data memiliki varian yang homogen. Dengan demikian populasi memiliki kesamaan varian atau homogeny.

\section{SIMPULAN}

Berdasarkan hasil penelitian dan hasil analisis data yang telah dilakukan terdapat perbedaan yang signifikan antara latihan massed dan distributed dalam meningkatkan kemampuan menggiring dribbling dalam permainan sepakbola dengan nilai distributed practice (32.64) lebih baik dari pada massed practiced (30.81)dalam meningkatkan kemampuan dribbling dalam permainan sepakbola pada pemain Green Boys. FC Selengen Usia 12-17. Peningkatan kemampuan dribbling pada pemain yang memiliki koordinasi mata-kaki tinggi lebih baik dari pada yang memiliki koordinasi mata-kaki rendah dengan rata-rata peningkatannya 35,34 dan 28,11.

\section{DAFTAR PUSTAKA}

Hariono, A. (2006). Metode melatih fisik pencak silat. FIK UNY.

Irianto, D. P. (2004). Bugar dan sehat dengan berolahraga. Andi Offset.

Mielke, D. (2007). Dasar-dasar sepak bola. Pakar Raya.

Miller, K. S. (2012). The effects on soccer dribbling skills when training with two different sized soccer balls. University of Kansas.

Schmidt, R. A., \& Wrisberg, C. A. (2008). Motor learning and performance: A situation-based learning approach. Human Kinetics.

Siswantoyo, S. (2014). Peningkatan power tungkai pesilat remaja melalui latihan pliometrik. Jurnal Cakrawala Pendidikan, 1(1). https://doi.org/10.21831/cp.v1i1.1864

Sudjana, S. (2002). Desain dan analisis eksperimen (Ed. 4). Tarsito.

Sukmadinata, N. S. (2015). Metode penelitian pendidikan. PT Remaja Rosdakarya. 